\title{
ENHANCED TECHNIQUE FOR REGRESSION TESTING
}

\author{
Arpit Agrawal ${ }^{1}$, Sanjay Babu Ahirwar ${ }^{2}$ \\ ${ }^{1}$ Lecturer, Computer Engineering, Institute of Engineering and Technology Indore, Madhya Pradesh India \\ ${ }^{2}$ Computer Engineering, Institute of Engineering and Technology Indore, Madhya Pradesh, India
}

\begin{abstract}
Regression testing perform where to retest modified version of software which already modified by developers on the basis of Feedback and testing of the software. Regression testing performs where no internal software knowledge and code known by the tester. Here all test cases not possible to retest this is a problem. So here we will use test case priority technique. that will provide priority to retest test case first. this test case priority technique uses for increase efficiency of regression testing. Because high priority test case execute first. and in our proposed technique we are set priority on the basis of [average time for execution(figure.1). which find out average time for execution on the basis of fault/time. and we will also ignore test cases which contain same average time for execution and we will select only one test cases in this situation.. After arrange test cases in descending order by average time of test cases execute test suite. This method gives more prioritization of test cases is compare to previous techniques. Finally we will get more prioritized test suite. Then we have also checked efficiency of this new method by APFD Metric [1]. Our primary purpose of this research paper to introduce new prioritization technique which provides better result is compare to previous techniques. which improves efficiency of Regression testing.
\end{abstract}

Keywords: Regression Testing, Prioritization, Test Case, Test Suite, APFD Metric[1].

\section{INTRODUCTION}

In this technique we are introducing a Enhanced technique of test case regression testing. Which improve performance and efficiency of regression testing. proposed technique sets priority on the basis of average time of execution. Many methodology are already exist but this technique increase efficiency of regression testing is compare to previously technique. These result we have compare by execute APFD metric also. Proposed technique can describe in these terms are :

Suppose $[\mathrm{T}]$ is The test suite which contain $\mathrm{n}$ no. of test cases [t] . like Test suite $\mathrm{T}=[\mathrm{t} 1 \ldots \ldots \ldots \ldots \ldots \ldots . \mathrm{tn}]$. And For set priority of ' $t$ ' we have calculated average time of execution of test cases by no. of fault / time. and one the basis of average time of execution we set order of test cases in decreasing order and those test cases contain same average time for execution ignore except any one. And again arrange $T^{\prime}$ ' in Descending order Then finally we will get more efficient test suite with priority. which will improve efficiency of regression testing. This efficiency we have also checked by APFD metric and we have improving efficiency of regression testing by using this proposed technique.

\section{Introduction of Regression testing :}

Regression testing perform for testing of software on modified version of software. Where tester does not know more about software development methodology and development code and development structure of the software.

After modified of software on the basis of feedback and testing of the software again require testing of software .here we performs regression testing for software faults. More about regression testing can be understand by figure no. 1.1

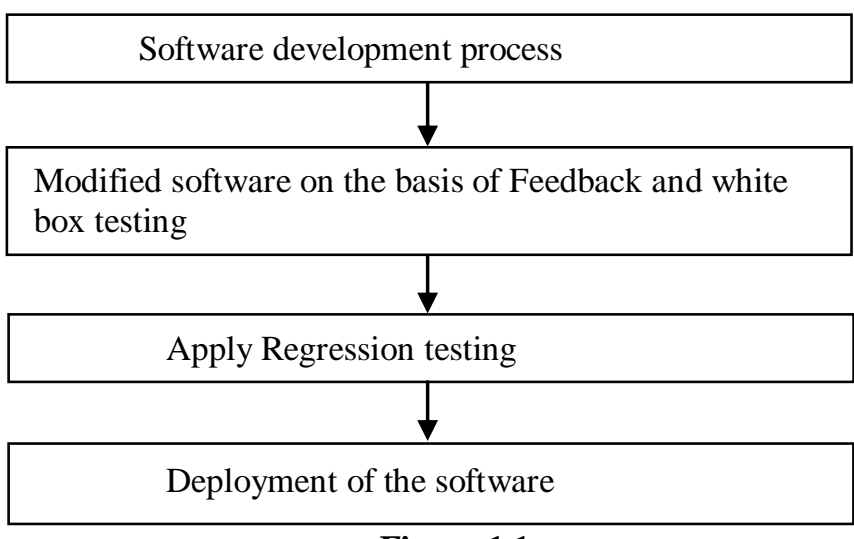

Figure 1.1

Already Available Methodology:

Many methodology and technique already provided by researchers for improve efficiency of regression testing .there include some regression techniques and prioritization technique also. For regression testing there are some methodology are already given are $[2,5,8,9]$

a) Again retest all test cases

b) Select test cases by regression

c) Reduce test case by algorithm

d) Arrange test cases in priority

\section{a) Again retest all test cases}

in this technique needs to retest all test cses of the modified software. This method take more time because every test cases needs to retest.

b) Select test cases by regression

In this technique needs to select some test cases on the basis of regression. And apply testing on these test cases. 
c) Reduce test cases by algorithm.

Test suite reduction technique is use for reduce redundant test cases during testing. Here if some redundancy arise in test cases like if two or more test cases are containing same faults on same time . these test cases ignored in test suite.

\section{d) Arrange test cases by priority.}

Arrange test cases by priority technique is efficient technique

Of regression testing . here arrange test cases by priority for test suite by performing some methods and techniques. Test case priority method can save time for retest all test cases.

Average percentage of faults detected(APFD) metric We are use APFD metric to compare efficiency of previous and our proposed techniques. which is developed by Elbaum the performance and efficiency of regression testing can be check by Average percentage of fault detected(APFD) metric $[11,1,2,4]$

Here $\mathrm{T}=$ The test suite under evaluation

$M=$ the number of faults contained in the program under test $\mathrm{t}$

$\mathrm{n}=$ The total number of test cases

tF I -> The position of the first test in t that exposes fault $i$.

$$
\mathrm{APFD}=1-\frac{\mathrm{tF} 1+\mathrm{tF} 2+\ldots \ldots \ldots+\mathrm{tFM}+1}{\mathrm{nM}}
$$

\section{PROPOSED WORK INTRODUCTION}

In this research paper we are introducing new technique for improve regression testing performance by using new test case priority technique where we are sets priority of test cases by calculate average time of execution of test case and arrange test cases in decreasing order. then we will ignore all test cases except one which are containing same average time of execution . then finally we get efficient prioritized test suite. we have also checked our technique performance by using APFD metric.

\section{ALGORITHM FOR PROPOSED TECHNIQUE}

Input for Algorithm:

- $\quad$ Non prioritized Test Suite $=\mathrm{T}$,

- $\quad$ Test cases of Test suite $=t$, and $\mathrm{t} \varepsilon \mathrm{T}$.

- No. of faults detected by a $\mathrm{t}=\mathrm{F}$,

- $\quad$ Time $=$ time

Step 1: begin

Step 2: $\quad$ select non prioritized $\mathrm{T}$

Step 3: for each test case t

$\varepsilon \mathrm{T}$

Step 4: for each test case $t=F /$ time
Step 5: arrange $\mathrm{T}$ in descending order on the basis of average time of execution of each test case.

Step 6: compare 'average time of execution' of all test cases.

Step 7: ignore test case those contain same average time of execution except one test case.

Step 8. again arrange $\mathrm{T}$ in descending order on the basis of 'average time of execution' value of each test case.

Step 9. finally Test suit $\mathrm{T}$ will be $\mathrm{T}$ '.

Step 10. end.

Result of Algorithm :

Prioritized Test suite T'.

\section{Determine Efficiency of Test Suite}

After using this technique test suite improves efficiency. because we are execute test cases with priority. Here high priority test case

Execute first which will make test suite efficient the efficiency of test suite we have also compare with the old and proposed technique by APFD metric. Finally we are getting more efficient test suite than previous techniques.

\section{Example :}

The following table for test suite $\mathrm{T}=[\mathrm{t} 1, \mathrm{t} 2, \mathrm{t} 3, \mathrm{t} 4, \mathrm{t} 5, \mathrm{t} 6, \mathrm{t} 7, \mathrm{t} 8, \mathrm{t} 9, \mathrm{t} 10]$ which contain Test case t1....t10 and Fault F1.....F10 and no. of fault and Time also mention there[Figure 1.2].

\begin{tabular}{|l|l|l|l|l|l|l|l|l|l|l|}
\hline & $\begin{array}{l}\mathrm{t} \\
1\end{array}$ & $\mathrm{t}$ & $\mathrm{t} 3$ & $\mathrm{t} 4$ & $\mathrm{t} 5$ & $\mathrm{t} 6$ & $\mathrm{t} 7$ & $\mathrm{t} 8$ & $\begin{array}{l}\mathrm{t} \\
9\end{array}$ & $\begin{array}{l}\mathrm{t} 1 \\
0\end{array}$ \\
\hline F1 & & & $*$ & & & & $*$ & & & \\
\hline F2 & $*$ & & & & & $*$ & & $*$ & & $*$ \\
\hline F3 & & & & & & & $*$ & & & \\
\hline F4 & $*$ & $*$ & & & $*$ & & $*$ & & & \\
\hline F5 & & & $*$ & & & & & & & $*$ \\
\hline F6 & & & & $*$ & & & & $*$ & & \\
\hline F7 & $*$ & & & & & & $*$ & & $*$ & \\
\hline F8 & & & & & $*$ & & $*$ & & & \\
\hline F9 & & $*$ & & $*$ & & $*$ & & & & $*$ \\
\hline F10 & & $*$ & & & & & & $*$ & & $*$ \\
\hline $\begin{array}{l}\text { No. } \\
\text { of } \\
\text { fault }\end{array}$ & 3 & 3 & 2 & 2 & 2 & 2 & 5 & 3 & 1 & 4 \\
\hline $\begin{array}{l}\text { Tim } \\
\text { e }\end{array}$ & 8 & 9 & 1 & 1 & 1 & 1 & 5 & 4 & 8 & 9 \\
\hline
\end{tabular}

Figure 1.2

APFD result by existing technique :

$$
\mathrm{APFD}=1-\frac{\mathrm{TF} 1+\mathrm{TF} 2+\ldots \ldots \ldots+\mathrm{TFm}+1}{\mathrm{~nm}}
$$




$$
\begin{gathered}
\mathrm{APFD}=1-\frac{3+1+7+1+3+4+1+5+2+2}{100}+\frac{1}{20} \\
=\mathbf{0 . 6 6} \text { or } 66 \%
\end{gathered}
$$

APFD result by new proposed technique :

$\mathrm{T}^{\prime}=[\mathrm{t} 1, \mathrm{t} 2, \mathrm{t} 3, \mathrm{t} 4, \mathrm{t} 5, \mathrm{t} 6, \mathrm{t} 7, \mathrm{t} 8, \mathrm{t} 9, \mathrm{t} 10]$

Firstly calculate Average time for execution -

$$
\begin{aligned}
& \mathrm{t} 1=3 / 8=0.37 \\
& \mathrm{t} 2=3 / 9=0.33 \\
& \mathbf{t 3}=\mathbf{2 / 1 6}=\mathbf{0 . 1 2} \\
& \mathrm{t} 4=2 / 11=0.18 \\
& \mathrm{t} 5=2 / 13=0.15 \\
& \mathrm{t} 6=2 / 14=0.14 \\
& \mathrm{t} 7=5 / 5=1 \\
& \mathrm{t} 8=3 / 4=0.75 \\
& \mathbf{t} 9=\mathbf{1 / 8}=\mathbf{0 . 1 2}
\end{aligned}
$$

$\mathrm{t} 10=4 / 9=0.44$

Now after arrange all test cases in descending order :

$\mathrm{T}^{\prime}=[\mathrm{t} 7, \mathrm{t} 8, \mathrm{t} 10, \mathrm{t} 1, \mathrm{t} 2, \mathrm{t} 4, \mathrm{t} 5, \mathrm{t} 6, \mathrm{t} 3, \mathrm{t} 9]$

Here $\mathrm{t} 3$ and $\mathrm{t} 9$ are same Average time of execution So

Finally

Test suite $T^{\prime}=[\mathrm{t} 7, \mathrm{t} 8, \mathrm{t} 10, \mathrm{t} 1, \mathrm{t} 2, \mathrm{t} 4, \mathrm{t} 5, \mathrm{t} 6, \mathrm{t} 3]$

And figure for Test suite $=\mathrm{T}^{\prime}$ :

\begin{tabular}{|l|l|l|l|l|l|l|l|l|l|}
\hline & $\mathrm{t} 7$ & $\mathrm{t} 8$ & $\mathrm{t} 10$ & $\mathrm{t} 1$ & $\mathrm{t} 2$ & $\mathrm{t} 4$ & $\mathrm{t} 5$ & $\mathrm{t} 6$ & $\mathrm{t} 3$ \\
\hline $\mathrm{F} 1$ & $*$ & & & & & & & & $*$ \\
\hline $\mathrm{F} 2$ & & $*$ & $*$ & $*$ & & & & $*$ & \\
\hline $\mathrm{F} 3$ & $*$ & & & & & & & & \\
\hline $\mathrm{F} 4$ & $*$ & & & $*$ & $*$ & & $*$ & & \\
\hline $\mathrm{F} 5$ & & & $*$ & & & & & & $*$ \\
\hline $\mathrm{F} 6$ & & $*$ & & & & $*$ & & & \\
\hline $\mathrm{F} 7$ & $*$ & & & $*$ & & & & & \\
\hline $\mathrm{F} 8$ & $*$ & & & & & & $*$ & & \\
\hline F9 & & & $*$ & & $*$ & $*$ & & $*$ & \\
\hline F10 & & $*$ & $*$ & & $*$ & & & & \\
\hline $\begin{array}{l}\text { No. } \\
\text { of } \\
\text { fault }\end{array}$ & 5 & 3 & 4 & 3 & 3 & 2 & 2 & 2 & 2 \\
\hline Time & 5 & 4 & 9 & 8 & 9 & 11 & 13 & 14 & 16 \\
\hline
\end{tabular}

$\mathrm{APFD}=1-\frac{1+2+1+1+3+2+1+1+3+2}{100}+1$

$=0.78$ or $78 \%$

result can compare by this figure are -

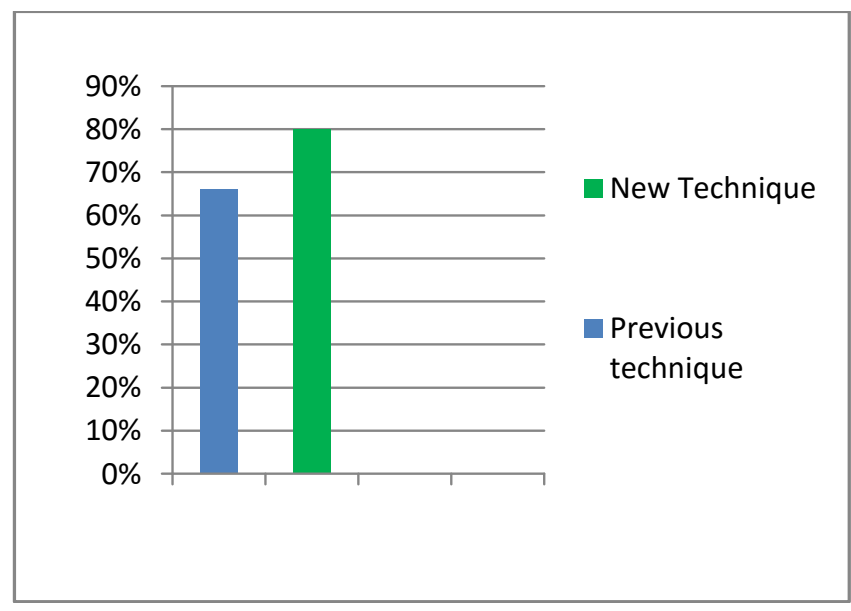

\section{CONCLUSION}

By applying this propose technique on regression testing . we are getting more efficiency of regression testing using prioritized test cases. We have compare result of previous and new technique by APFD[1,11] metric . that shows our new technique is efficient.

Primary purpose of this research paper is to introduce to set efficient Priority of test cases and enhanced prioritization technique of Regression testing.

\section{REFERENCES}

[1] Alexey G. Malishevsky, Joseph R. Ruthruff, Gregg Rothermel, Sebastian Elbaum, Costcognizant Test Case Prioritization, 2006

[2] S. Elbaum, A. Malishevsky, and G.Rothermel Test case prioritization: A family of empirical studies.

IEEE Transactions on Software Engineering, February 2002.

[3] Roger S. Pressman, Software engineering a practitioner's approach 6/e, 2005

[4] SebastianElbaum, Gregg Rothermel, SatyaKanduri, Alexey G. Malishevsky, Selecting a Cost-Effective Test Case Prioritization Technique, April 2004

[5] Aditya P.Mathur, Foundation of software testing, Pearson Education 1st edition.

[6] MaruanKhoury, Cost-Effective Regression Testing, 2006

[7] G. Rothermel, R.H. Untch, C. Chu, and M.J. Harrold, "Prioritizing Test Cases for Regression

Testing," IEEE Trans. Software Eng., vol. 27, no. 10, pp. 929-948, Oct. 2001.

[8] MaruanKhoury, Cost-Effective Regression Testing, 2006

[9] M. Thillaikarasi ,K. Seetharam ,Techniques on Regrassion testing

[10]Shin Yoo, Mark Harman,Regression Testing Minimization, Selection and Prioritization : A Survey [11]Rothermel, G., and Harrold, M.J., "Analysing regression test Selection Techniques", IEEE Transactions on Software Engineering,vol.22,no . 8 ,pp.529-551 Aug.1996. 